\title{
Avaliação do ensino prático desenvolvido em um hospital universitário na perspectiva de graduandos em Enfermagem
}

Assessment of practical teaching in a university hospital according the view of nursing undergraduate students

Evaluación de la enseñanza práctica en hospital universitario desarrollado en la perspectiva de estudiantes de enfermería

Vera Lucia Mira ${ }^{\mathrm{I}}$, Valéria Garcia Lopes Araujo ${ }^{\mathrm{II}}$, Lígia Fumiko Minami ${ }^{\mathrm{III}}$, Daisy Maria Rizatto Tronchin $^{\mathrm{IV}}$, Antônio Fernandes Costa Limav, Eloá Otrenti ${ }^{\mathrm{VI}}$, Maria Helena Trench Ciampone ${ }^{\mathrm{VII}}$

\section{RESUMO}

Buscando condições apropriadas para formação de enfermeiros críticos e reflexivos, este estudo objetivou avaliar, na perspectiva dos graduandos da Escola de Enfermagem da Universidade de São Paulo (USP), o ensino prático desenvolvido no Hospital Universitário. Trata-se de estudo quantitativo descritivo com população de 77 graduandos de enfermagem, que cursavam $8^{\circ}$ período em 2007 e 2008 . A coleta de dados ocorreu por meio de escala psicométrica testada e validada previamente. Os resultados mostraram que os enfermeiros dispensaram atenção aos graduandos e oportunidades de aprendizagem na dinâmica de trabalho e forneceram orientações objetivas e seguras; estimularam o raciocínio clínico visando à tomada de decisão e planejamento da assistência de enfermagem, discutindo a dimensão ética. Os graduandos sentiram-se respeitados e integrados à equipe. As atividades práticas desenvolvidas no Hospital da USP atenderam aos objetivos das diversas disciplinas, estabelecendo relação teoria e prática e colaborando na construção da identidade profissional dos futuros enfermeiros. Este estudo permitirá o aprimoramento do campo em consonância com o projeto político pedagógico da Escola.

Descritores: Enfermagem; Educação; Avaliação.

\section{ABSTRACT}

In order to seeking proper conditions for training critical and reflective nurses, this study aims to evaluate according the perspective of students of the 8th semester of the School of Nursing, University of Sao Paulo, the practice developed at the Hospital of the University. It is a quantitative, exploratory and descriptive study. The population consisted of 77 students that were studying at the 8 th period of the course in 2007 and 2008. Data collection occurred through psychometric scale previously tested and validated. The results showed that nurses have spent attention to the students and offered opportunities for their learning concerning the work dynamics of the units. Also, they provided objective and safe advices, discussing the ethical aspects of the care. Furthermore they stimulated the development of clinical reasoning for decision-making, and for planning the nursing care. , The students fell respected and integrated into the team. The practical activities developed in the USP Hospitals provided to establish the relationship between theory and practice and contributed to the construction of professional identity of future nurses. This study will contribute to improving the training field according to the political pedagogical project.

Descriptors: Nursing, Education, Assessment.

\section{RESUMEN}

Con finalidad de buscar condiciones adecuadas a enseñanza de enfermeros críticos y reflexivos, este estudio objetivó evaluar la enseñanza practica desarrollada en hospital escuela, según estudiantes de Escuela de Enfermería - Universidad de São Paulo (USP). Estudio cuantitativo descriptivo con 77 estudiantes de enfermería del $8^{\circ}$ período, en 2007 y 2008 . Datos fueron recogidos por escala psicométrica probada y validada previamente. Los resultados mostraron que enfermeros ofrecen oportunidad de aprendizaje dinámica del trabajo, orientaciones objetivas y confiables, estimularon el razonamiento clínico objetivando la tomada de decisiones y planeamiento de asistencia de enfermería según dimensión ética. Los estudiantes se cayeron respeto y integrados con el equipo. Actividades practicas desarrolladas en el hospital proporcionaron alcance de objetivos de disciplinas, estableciéndose relaciones entre teoría-practica, y colaborando en la construcción de la identidad profesional con futuros enfermeros. Este estudio contribuirá con el campo de entrenamiento basándose en Proyecto Político Pedagógico de la Escuela.

Descriptores: Enfermería; Educación; Evaluación.

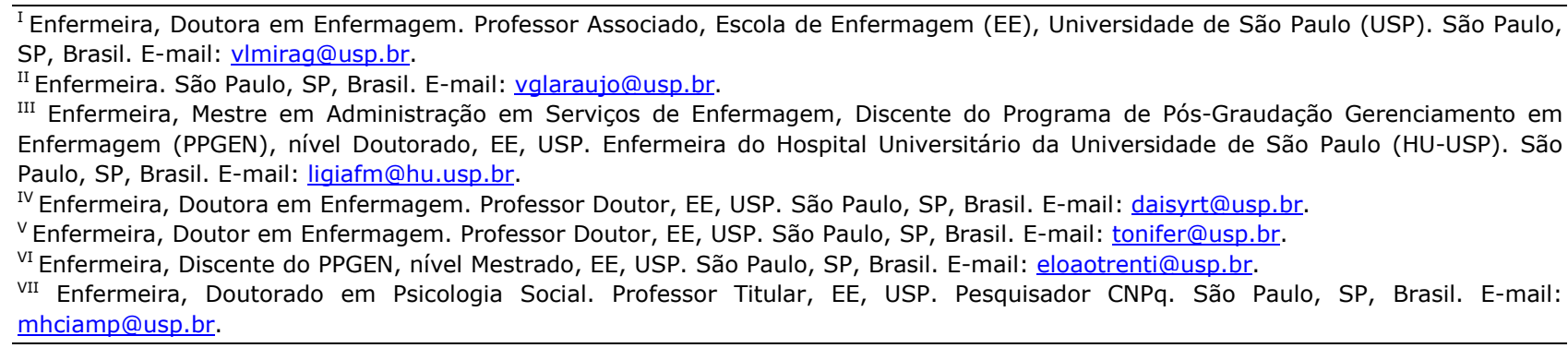




\section{INTRODUÇÃO}

A formação de enfermeiros críticos, com capacidade de reflexão e de participação efetiva na resolução dos problemas do sistema de saúde está, entre outros fatores, relacionada à observância das exigências da Lei de Diretrizes e Bases (LDB) e das Diretrizes Curriculares Nacionais $(\mathrm{DCN})^{(1)}$, transcendendo a dimensão técnica do ensino e do cuidado e valorizando as dimensões éticas e humanísticas que desenvolvem, no aluno, atitudes e valores orientados para a cidadania e para a solidariedade ${ }^{(2)}$.

As DCN visam nortear as Instituições de Ensino Superior (IES) para a implantação de projetos políticopedagógicos que não se constituem em fórmulas prontas, pois as IES estão sob a égide do contexto sóciopolítico-cultural e a exigência de formas inovadoras de saber, fazer e $\operatorname{ser}^{(3)}$.

A atenção à DCN implica, ainda, construir, coletivamente, um projeto pedagógico focado no aluno como sujeito da aprendizagem, sendo apoiado pelo professor que assume papel de facilitador do processo ensino-aprendizagem ${ }^{(2)}$. Ademais, considerando que, historicamente, a enfermagem busca adequar-se às determinações sociais e legais das políticas e conquistar sua autonomia enquanto profissão da saúde ${ }^{(4)}$, a formação do enfermeiro é um dos desafios para as instituições de ensino e para o Sistema Único de Saúde, levando à reflexão de 'como' e 'para quê' formamos os profissionais de saúde ${ }^{(5)}$.

A articulação e corresponsabilidade dos sistemas de saúde e de educação na formação dos profissionais de saúde iniciamse no sistema de saúde que disponibiliza o cenário prático do processo ensino-aprendizagem ${ }^{(5)}$. A aprendizagem ocorre num processo com sucessivas aproximações da realidade, nas quais os discentes vivenciam situações em que partilham conhecimentos e conflitos, reconhecendo a necessidade do trabalho grupal e em equipe. Evidencia, ainda, que a inserção dos professores nos serviços de saúde, por meio da parceria, é um dos determinantes no movimento de ação-reflexão-ação transformadora ${ }^{(6)}$.

Nesse sentido, a integração docente-assistencial pode contribuir para diminuir as fronteiras entre os sistemas de ensino e de saúde, encaminhando-se para a definição de estratégias pedagógicas que articulem o aprender e o saber fazer, ser e conviver, tomando-os como atributos indispensáveis à formação do enfermeiro(2).

A aproximação teórica e reflexiva, apoiada pelo docente, resulta na ampliação da compreensão do estudante acerca da intersecção entre gerenciamento e cuidado e entre outros objetivos do processo de ensinoaprendizado $^{(7)}$. Assim, o desempenho no decorrer das atividades depende, também, do esforço e habilidade individual do estudante e de sua interação com o coletivo $^{(8)}$.

Sob esse prisma, este estudo teve o propósito de analisar aspectos do processo de trabalho e da organização de saúde que interferem na qualidade do ensino e, consequentemente, da aprendizagem.

A Escola de Enfermagem (EE) da Universidade de São Paulo (USP) e o Departamento de Enfermagem (DE) do Hospital Universitário (HU) da USP, desde sua inauguração em 1981, vêm desenvolvendo programas e ações visando à integração docente assistencial.

Grande parte do ensino prático da $E E$, embasado na tríade aluno-professor-profissional, acontece, desde o 30 semestre da graduação, nas unidades do $\mathrm{HU}$ abrangendo as grandes áreas de Saúde do Adulto, da Criança, da Mulher, Saúde Coletiva e Administração em Enfermagem. As atividades de ensino-aprendizagem são coordenadas pelas docentes da EE com a participação efetiva da equipe de enfermagem, objetivando oferecer ao aluno a possibilidade de questionamento, discussão, análise, proposição de soluções de problemas e tomada de decisão em situações reais da assistência e da gerência, reforçando a proximidade entre a área acadêmica e o trabalho.

Os estudantes aprendem, dentre outras formas, pela observação e análise crítica de seus instrutores, bem como pela adaptação aos contextos sociais nos quais se inserem, compartilhando experiências e saberes. No HU, os alunos da EE são acompanhados pelo docente ou, em algumas disciplinas, permanecem, no cotidiano do trabalho, sob a supervisão direta do enfermeiro que atua como preceptor, sendo o professor um mediador do processo de ensino-aprendizagem. Nessa dinâmica, a busca do conhecimento parte do próprio aluno, cabendo ao enfermeiro e ao professor, estimularem e despertarem essa atitude, o alcance de metas de aprendizagem e o desenvolvimento de competências para o exercício profissional.

Com a finalidade de atender às necessidades e às expectativas de estudantes, docentes e profissionais no tocante à formação do enfermeiro e promover condições favoráveis ao processo de ensino-aprendizagem, é essencial avaliar o campo onde se desenvolve a formação do graduando, identificando os fatores intervenientes.

Desse modo, e relevando o protagonismo do estudante, é essencial conhecer sua opinião a respeito das condições de ensino oferecidas no $\mathrm{HU}$, bem como conhecer a capacitação e o envolvimento dos enfermeiros no processo educacional. 
Essa avaliação vinha sendo realizada, informalmente, no momento da avaliação de desempenho do aluno, quando este tinha a oportunidade de opinar a respeito da interação estudante/equipe de enfermagem, dos recursos disponíveis para o desenvolvimento da prática e do preparo dos profissionais de enfermagem para acompanhar as atividades discentes, entre outros. Com vistas a elaborar estratégias e implementar ações para atingir a excelência do processo de formação do enfermeiro, enfermeiros do Serviço de Apoio Educacional (SEd) do $\mathrm{HU}$ e docentes do Departamento de Orientação Profissional da EE, iniciaram um processo formal de avaliação, inicialmente, na perspectiva do discente.

Embora o ensino prático da EE ocorra em diversos equipamentos de saúde, optamos por analisar o HU devido à articulação docente-assistencial que facilita o processo de mudanças. Essa estratégia de avaliação poderá ser aperfeiçoada para aplicação nos demais locais de ensino prático.

Assim, este estudo teve como objetivo geral avaliar, sob a óptica dos alunos do $8^{\circ}$ semestre de graduação, o ensino prático do curso de graduação em enfermagem da Escola de Enfermagem desenvolvido no Hospital Universitário da Universidade de São Paulo; como específicos, propõe-se a identificar os aspectos facilitadores e os pontos vulneráveis do Hospital enquanto local para o ensino prático e formação do estudante e comparar as avaliações dos graduandos do $8^{\circ}$ semestre dos anos de 2007 e 2008.

\section{MATERIAL E MÉTODO}

Trata-se de uma pesquisa exploratória, descritiva com abordagem quantitativa, realizada na EE da USP, após aprovação do Comitê de Ética em Pesquisa da mesma (619/2007 CEPEEUSP) e o apoio e a anuência do DE do HU.

A população foi composta por 144 alunos do $8^{\circ}$ semestre do curso de graduação em enfermagem da EE dos anos de 2007 (79 alunos) e 2008 (65 alunos), destes, integraram a pesquisa respondendo ao questionário 45 e 32, respectivamente, totalizando 77 $(53,5 \%)$ sujeitos de pesquisa. A opção pelos graduandos do $8^{\circ}$ semestre se deu em virtude destes terem desenvolvido atividades práticas no $\mathrm{HU}$, garantindo uma opinião fundada na experiência. Além disso, permite a comparação entre os grupos para conhecer diferentes ou convergentes perspectivas.

Para captar do aluno sua percepção a respeito das atividades práticas desenvolvidas no $\mathrm{HU}$ e identificar os graus do mais favorável ao mais desfavorável, optamos pela construção e aplicação de uma escala psicométrica, contendo cinco intervalos de concordância: Discordo totalmente (DT); Discordo (D); Nem concordo, nem discordo (NCND); Concordo (C); Concordo totalmente (CT). Essa medida gradual varia de intensidade, alta ou baixa e de direção, positiva ou negativa, em relação ao objeto em apreciação( ${ }^{(9)}$.

A construção deste instrumento fundamentou-se em quatro categorias definidas, a priori, expressando os fatores que se pretendia avaliar, considerando condições para o desenvolvimento da aprendizagem prática, tais como, relacionamento interpessoal, recursos humanos e materiais nos aspectos quantitativos e qualitativos.

A primeira categoria pretendeu identificar competências relacionadas ao Preparo do enfermeiro para supervisionar o estágio dos estudantes, considerando, entre outros, domínio técnico do profissional e segurança do aluno ao ser supervisionado pelo enfermeiro. A segunda categoria destacou fatores acerca do Relacionamento interpessoal do estudante com a equipe de enfermagem, abordando seu acolhimento pela equipe e 0 respeito da equipe para com eles. A terceira categoria propôs-se a analisar o Aproveitamento do estudante no campo no que se refere à construção gradativa da identidade profissional e a relação entre teoria e prática. A quarta categoria foi atinente às Condições institucionais oferecidas ao estudante, como recursos humanos e materiais disponíveis para o desenvolvimento da prática, disponibilidade e utilidade dos instrumentos de enfermagem e articulação docente-assistencial.

Ressaltamos que a palavra "estágio" foi introduzida na escala com o significado do senso comum concernente às atividades de ensino práticas, linguagem habitual do aluno, não se refere, portanto, ao estágio curricular supervisionado descrito na $\mathrm{DCN}^{(2)}$, embora algumas disciplinas apresentem tais características.

Para verificar a compreensão dos alunos acerca das proposições elaboradas, a escala foi submetida a teste piloto junto a graduandos do 70 semestre de 2006. Com vistas a verificar a validade e confiabilidade da escala, esta foi submetida à apreciação segundo validade de conteúdo e critérios de consistência interna.

O critério de validade de conteúdo ou validação de juízes $^{(9)}$ tem como objetivo verificar se o conteúdo da escala é representativo frente ao universo teórico que se pretende medir.

Para tal, a escala foi submetida à apreciação de sete juízes, docentes com experiência no acompanhamento de atividades práticas de ensino realizadas no âmbito hospitalar e com conhecimento acerca do método de 
escala intervalar. Os juízes analisaram, em cada item da escala, os critérios de relevância e clareza e pertinência à categoria; opinaram sobre a necessidade de inclusão ou exclusão de algum item componente da escala; a adequação da quantidade e da descrição de graus para mensuração proposta, além de tecerem comentários e sugestões. As alterações sugeridas foram realizadas.

A consistência interna é uma das condições de confiabilidade e refere-se à consistência e coerência com que o instrumento mede um determinado atributo; quanto menor a variação produzida nas mensurações repetidas de um atributo, maior a sua confiabilidade ${ }^{(5)}$. Essa medida foi obtida pelo Alpha de Cronbach que varia de zero a um, sendo mais consistente quanto mais próxima de um. Neste estudo, os valores de Alpha de Cronbach 0.431241 em 2007 e 0.645821 em 2008.

A coleta de dados ocorreu nos meses de outubro de 2007 e setembro de 2008 por meio eletrônico ou na forma impressa. O instrumento de coleta de dados foi acompanhado de uma carta de apresentação indicando que o estudante deveria emitir sua opinião a respeito de suas experiências práticas realizadas no HU durante todo o período de graduação, acrescido ainda de uma folha de instrução orientando o modo como o estudante deveria responder à escala. O prazo para responder e recolher o instrumento foi de, aproximadamente, uma semana.

A análise se deu por meio de estatística descritiva e medidas de tendência central. Para comparação dos grupos de 2007 e 2008 foi calculado escore total e escores por categoria e aplicado teste não paramétrico de Mann-Whitney, com nível de significância de $5 \%$.

Os estudantes que concordaram, espontaneamente, em participar da pesquisa, após os devidos esclarecimentos, receberam o Termo de Responsabilidade do Pesquisador. A opção por esse tipo de termo baseou-se na possibilidade de propiciar maior espontaneidade aos estudantes pelo fato de não haver necessidade de assinatura, sendo que a devolução do instrumento preenchido significava a concordância do sujeito.

\section{RESULTADOS}

Com relação à caracterização dos estudantes, 93,8\% eram do sexo feminino em 2007 e 98,8\% em 2008. A faixa etária predominante foi de 22 a 25 anos, sendo $93,3 \%$ em 2007 e 75,1\% em 2008.

Os resultados das Tabelas 1, 2, 3 e 4 mostram a distribuição da graduação por questão em cada categoria. 
Tabela 1: Distribuição percentual das respostas por questão da Categoria 1 "Preparo do enfermeiro para supervisionar o estágio dos alunos", por ano. São Paulo, SP, 2008.

\begin{tabular}{|c|c|c|c|c|c|c|c|c|c|c|}
\hline \multirow{2}{*}{$\begin{array}{c}\text { Graduação } \\
\text { Questões/Ano }\end{array}$} & \multicolumn{2}{|c|}{ DT } & \multicolumn{2}{|c|}{ D } & \multicolumn{2}{|c|}{ NCND } & \multicolumn{2}{|c|}{$\mathbf{C}$} & \multicolumn{2}{|c|}{ CT } \\
\hline & 2007 & 2008 & 2007 & 2008 & 2007 & 2008 & 2007 & 2008 & 2007 & 2008 \\
\hline 1. A atenção que os enfermeiros disponibilizaram aos alunos, facilitou a aprendizagem. & 0,0 & 0,0 & 15,6 & 3,1 & 0,0 & 3,1 & 51,1 & 56,3 & 33,3 & 37,5 \\
\hline 2. Os enfermeiros poderiam assumir, integralmente, o acompanhamento do estágio. & 11,1 & 0,0 & 33,3 & 21,9 & 11,1 & 12,5 & 28,9 & 34,4 & 15,6 & 28,1 \\
\hline 3. Senti-me seguro ao ser supervisionado pelos enfermeiros. & 4,4 & 0,0 & 6,7 & 3,1 & 13,3 & 6,3 & 48,9 & 43,8 & 26,7 & 46,9 \\
\hline 6. Os enfermeiros estimularam os alunos a aprenderem. & 0,0 & 0,0 & 13,3 & 6,3 & 22,2 & 12,5 & 51,1 & 40,6 & 13,3 & 40,6 \\
\hline $\begin{array}{l}\text { 7. Houve divergências entre aquilo que os enfermeiros orientavam e aquilo que os técnicos e auxiliares de } \\
\text { enfermagem realizavam. }\end{array}$ & 2,2 & 0,0 & 33,3 & 28,1 & 22,2 & 18,8 & 26,7 & 50,0 & 15,6 & 3,1 \\
\hline 11. Fui estimulado pelos enfermeiros a desenvolver o raciocínio clínico. & 0,0 & 0,0 & 13,3 & 3,1 & 22,2 & 6,3 & 48,9 & 68,8 & 15,6 & 21,9 \\
\hline 12. Os enfermeiros possuíam domínio técnico de suas atividades. & 0,0 & 0,0 & 4,4 & 0,0 & 8,9 & 0,0 & 48,9 & 59,4 & 37,8 & 40,6 \\
\hline 19. Os enfermeiros ajudaram os alunos a encontrarem oportunidades de aprendizagem. & 0,0 & 0,0 & 2,2 & 6,3 & 15,6 & 12,5 & 64,4 & 62,5 & 17,8 & 18,8 \\
\hline 20. As orientações prestadas pelos enfermeiros aos alunos foram objetivas e consistentes. & 0,0 & 0,0 & 8,9 & 3,1 & 15,6 & 6,3 & 57,8 & 71,9 & 17,8 & 18,8 \\
\hline 22. Os enfermeiros não têm segurança para assumir a condução do estágio dos alunos. & 26,7 & 25,0 & 40,0 & 50,0 & 20,0 & 12,5 & 11,1 & 6,4 & 2,2 & 3,1 \\
\hline 24. Os enfermeiros se esforçaram para favorecer o aprendizado dos alunos. & 0,0 & 0,0 & 15,6 & 3,1 & 13,3 & 15,6 & 57,8 & 56,3 & 13,3 & 25,0 \\
\hline 25. Houve divergências entre as orientações ministradas pelos enfermeiros aos alunos. & 13,3 & 12,5 & 48,9 & 37,5 & 17,8 & 18,8 & 13,3 & 28,1 & 6,7 & 3,1 \\
\hline 26. Os enfermeiros não estavam preparados para acompanhar os alunos nos estágios. & 28,9 & 31,3 & 37,8 & 59,4 & 13,3 & 6,3 & 15,6 & 3,1 & 4,4 & 0,0 \\
\hline 27. Os enfermeiros tinham receio que os alunos cometessem falhas. & 4,4 & 3,1 & 40,0 & 31,3 & 22,2 & 31,3 & 22,2 & 31,3 & 11,1 & 3,1 \\
\hline 30. Os enfermeiros contribuíram para otimização do tempo de estágio. & 2,2 & 0,0 & 20,0 & 3,1 & 28,9 & 21,9 & 44,4 & 62,5 & 4,4 & 12,5 \\
\hline 32. Fui encorajado a participar da dinâmica de trabalho da unidade. & 2,2 & 0,0 & 8,9 & 3,1 & 24,4 & 3,1 & 46,7 & 71,9 & 17,8 & 21,9 \\
\hline 37. Os enfermeiros precisam ensinar ao aluno conteúdos que eles mesmos desconhecem. & 20,0 & 21,9 & 40,0 & 46,9 & 31,1 & 21,9 & 6,7 & 9,4 & 2,2 & 0,0 \\
\hline 40. Os enfermeiros apresentavam dificuldade para compartilhar seu conhecimento com os alunos. & 6,7 & 25,0 & 62,2 & 56,3 & 13,3 & 12,5 & 17,8 & 6,3 & 0,0 & 0,0 \\
\hline
\end{tabular}

Legenda: Discordo totalmente (DT); Discordo (D); Nem concordo, nem discordo (NCND); Concordo (C); Concordo totalmente (CT)

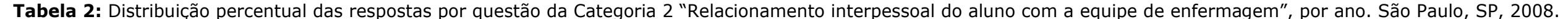

\begin{tabular}{|c|c|c|c|c|c|c|c|c|c|c|}
\hline \multirow{2}{*}{$\begin{array}{c}\text { Graduação } \\
\text { Questão/Ano }\end{array}$} & \multicolumn{2}{|c|}{ DT } & \multicolumn{2}{|c|}{ D } & \multicolumn{2}{|c|}{ NCND } & \multicolumn{2}{|c|}{$\mathbf{C}$} & \multicolumn{2}{|c|}{ CT } \\
\hline & 2007 & 2008 & 2007 & 2008 & 2007 & 2008 & 2007 & 2008 & 2007 & 2008 \\
\hline 5. Nem sempre fui bem acolhido pela equipe de enfermagem. & 13,3 & 12,5 & 31,1 & 40,6 & 11,1 & 9,4 & 40,0 & 31,3 & 4,4 & 6,3 \\
\hline 9. Os enfermeiros foram atenciosos para com os alunos. & 0,0 & 0,0 & 6,7 & 9,4 & 8,9 & 3,1 & 53,3 & 53,1 & 31,1 & 34,4 \\
\hline 13. Fui respeitado pelos profissionais da equipe de enfermagem nas unidades de estágio. & 0,0 & 0,0 & 11,1 & 0,0 & 13,3 & 12,5 & 46,7 & 59,4 & 28,9 & 28,1 \\
\hline 15. Não consegui me entrosar com a equipe de enfermagem. & 42,2 & 43,8 & 42,2 & 53,1 & 11,1 & 3,1 & 4,4 & 0,0 & 0,0 & 0,0 \\
\hline 29. Não existe interação entre alunos e equipe de enfermagem. & 51,1 & 37,5 & 37,8 & 56,3 & 4,4 & 3,1 & 6,7 & 3,1 & 0,0 & 0,0 \\
\hline
\end{tabular}

Legenda: Discordo totalmente (DT); Discordo (D); Nem concordo, nem discordo (NCND); Concordo (C); Concordo totalmente (CT) 
Tabela 3: Distribuição percentual das respostas por questão da Categoria 3 "Aproveitamento do aluno no campo", por ano. São Paulo, SP, 2008.

\begin{tabular}{|c|c|c|c|c|c|c|c|c|c|c|}
\hline \multirow{2}{*}{$\begin{array}{c}\text { Graduação } \\
\text { Questão/Ano }\end{array}$} & \multicolumn{2}{|c|}{ DT } & \multicolumn{2}{|c|}{ D } & \multicolumn{2}{|c|}{ NCND } & \multicolumn{2}{|c|}{ C } & \multicolumn{2}{|c|}{ CT } \\
\hline & 2007 & 2008 & 2007 & 2008 & 2007 & 2008 & 2007 & 2008 & 2007 & 2008 \\
\hline 8. Os estágios proporcionaram a construção gradativa de minha identidade profissional. & 0,0 & 0,0 & 0,0 & 0,0 & 2,2 & 0,0 & 42,2 & 46,9 & 55,6 & 53,1 \\
\hline 17. Os estágios contribuíram somente para o aprendizado técnico. & 40,0 & 50,0 & 44,4 & 46,9 & 8,9 & 0,0 & 4,4 & 3,1 & 2,2 & 0,0 \\
\hline 21. Os estágios atenderam às minhas expectativas. & 2,2 & 0,0 & 15,6 & 0,0 & 15,6 & 3,1 & 51,1 & 75,0 & 15,6 & 21,9 \\
\hline 28. Foi possível discutir com os enfermeiros os aspectos éticos relacionados à prática profissional. & 8,9 & 9,4 & 15,6 & 15,6 & 22,2 & 9,4 & 44,4 & 50,0 & 8,9 & 15,6 \\
\hline 36. As atividades realizadas foram suficientes para atender aos objetivos de cada estágio. & 4,4 & 0,0 & 33,3 & 12,5 & 17,8 & 21,9 & 33,3 & 53,1 & 11,1 & 12,5 \\
\hline 39. Consegui relacionar teoria e prática durante os estágios.* & 0,0 & 3,1 & 4,4 & 0,0 & 8,9 & 0,0 & 55,6 & 56,3 & 31,1 & 37,5 \\
\hline
\end{tabular}

*Um estudante não respondeu à questão 39 , o que corresponde a $3,1 \%$.

Legenda: Discordo totalmente (DT); Discordo (D); Nem concordo, nem discordo (NCND); Concordo (C); Concordo totalmente (CT)

Tabela 4: Distribuição percentual das respostas por questão da Categoria 4 "Condições institucionais oferecidas ao aluno", por ano. São Paulo, 2008.

\begin{tabular}{|c|c|c|c|c|c|c|c|c|c|c|}
\hline \multirow{2}{*}{$\begin{array}{c}\text { Graduação } \\
\text { Questão/Ano }\end{array}$} & \multicolumn{2}{|c|}{ DT } & \multicolumn{2}{|c|}{ D } & \multicolumn{2}{|c|}{ NCND } & \multicolumn{2}{|c|}{ C } & \multicolumn{2}{|c|}{ CT } \\
\hline & 2007 & 2008 & 2007 & 2008 & 2007 & 2008 & 2007 & 2008 & 2007 & 2008 \\
\hline 4. Os enfermeiros não tinham tempo para acompanhar os alunos. & 4,4 & 12,5 & 51,1 & 40,6 & 20,0 & 18,8 & 15,6 & 28,1 & 8,9 & 0,0 \\
\hline 10. Professores e enfermeiros tiveram uma boa interação. & 2,2 & 0,0 & 4,4 & 3,1 & 17,8 & 28,1 & 64,4 & 53,1 & 11,1 & 15,6 \\
\hline 14. Os enfermeiros precisam conhecer melhor os objetivos do estágio. & 2,2 & 6,3 & 24,4 & 37,5 & 13,3 & 15,6 & 33,3 & 21,9 & 26,7 & 18,8 \\
\hline 16. A falta de recursos humanos dificultou o desenvolvimento do estágio. & 24,4 & 18,8 & 42,2 & 62,5 & 17,8 & 6,3 & 13,3 & 12,5 & 2,2 & 0,0 \\
\hline 18. Presenciei a ocorrência de situações que desrespeitavam aspectos éticos da prática profissional. & 11,1 & 12,5 & 26,7 & 31,3 & 17,8 & 15,6 & 31,1 & 37,5 & 13,3 & 3,1 \\
\hline $\begin{array}{l}\text { 23. Frequentemente, a dinâmica de trabalho na unidade não permitiu que os enfermeiros me } \\
\text { acompanhassem durante o estágio. }\end{array}$ & 4,4 & 12,5 & 40,0 & 31,3 & 20,0 & 21,9 & 24,4 & 28,1 & 11,1 & 6,3 \\
\hline 31. Não houve uma boa comunicação entre os enfermeiros e os professores. & 20,0 & 21,9 & 40,0 & 50,0 & 20,0 & 12,5 & 17,8 & 15,6 & 2,2 & 0,0 \\
\hline 33. A falta de recursos materiais dificultou o desenvolvimento do estágio. & 55,6 & 40,6 & 37,8 & 56,3 & 4,4 & 3,1 & 2,2 & 0,0 & 0,0 & 0,0 \\
\hline 34. Tive possibilidade de consultar os manuais de enfermagem da unidade. & 4,4 & 3,1 & 8,9 & 9,4 & 11,1 & 12,5 & 35,6 & 50,0 & 40,0 & 25,0 \\
\hline $\begin{array}{l}\text { 35. O Sistema de Assistência de Enfermagem (SAE) constitui-se em um importante instrumento de } \\
\text { aprendizagem. }\end{array}$ & 0,0 & 0,0 & 2,2 & 3,1 & 2,2 & 3,1 & 40,0 & 50,0 & 55,6 & 43,8 \\
\hline $\begin{array}{l}\text { 38. A unidade proporcionou condições para que eu buscasse oportunidades para realizar os procedimentos } \\
\text { previstos em cada estágio. }\end{array}$ & 2,2 & 0,0 & 8,9 & 6,3 & 13,3 & 18,8 & 60,0 & 59,4 & 15,6 & 15,6 \\
\hline 41. Os manuais de enfermagem foram úteis para o meu aprendizado. & 4,4 & 0,0 & 2,2 & 6,3 & 26,7 & 25,0 & 46,7 & 62,5 & 20,0 & 6,3 \\
\hline 42. Os enfermeiros estão preparados para ensinar o aluno sobre o Diagnóstico de Enfermagem. & 2,2 & 0,0 & 17,8 & 6,3 & 20,0 & 12,5 & 51,1 & 56,3 & 8,9 & 25,0 \\
\hline
\end{tabular}

Legenda: Discordo totalmente (DT); Discordo (D); Nem concordo, nem discordo (NCND); Concordo (C); Concordo totalmente (CT) 
Os resultados da Categoria 1, Tabela 1, mostram predominância no intervalo de concordância nas questões $1,3,6,11,12,19,20,24$ e 32 nos dois anos avaliados, e nas questões 2 e 8 em 2008; a discordância predominou nas questões 22, 25, 26, 37 e 40 em 2007 e 2008, na 27 em 2007 e na 7 em 2008; não houve tendência nas questões 2, 7 e 30 em 2007, e na 27 em 2008.

A Tabela 2 mostra que na Categoria 2 houve prevalência de concordância nas questões 9 e 13 e discordância nas 15 e 29, nos dois anos estudados; na questão 5, a maioria dos estudantes de 2008 discordou e em 2007 não houve tendência.

Com relação à Categoria 3, Tabela 3, o intervalo de concordância foi maior nas questões 8, 21, 28 e 39; de discordância na 17 nos dois anos; na 36 não houve tendência em 2007 e em 2008 prevaleceu a concordância.

$\mathrm{Na}$ Categoria 4, Tabela 4, observamos, nos dois anos, que preponderou a concordância nas questões 10 , 34, 35, 38, 41 e 42; a discordância nas 4, 16, 31 e 33 e sem tendência nas 18 e 23. Já na questão 14, a discordância predominou em 2007 e não apresentou tendência em 2008.

Ressaltamos que nas questões com direção negativa $(7,22,25,26,27,37,40,5,15,17,4,14,16,18,23$, 31 e 33) ao objeto de estudo, a discordância é que mostra a dimensão favorável.

A comparação dos grupos de graduandos de 2007 e 2008 mostrou que os grupos diferem em relação ao escore nas categorias $1(p=0,001)$ e $2(p<0,001)$, sendo que o grupo de 2007 apresenta valor de escore significantemente menor que o do grupo de 2008 nas duas categorias. Embora tenha havido diferenças no comportamento das respostas de um para o outro, os grupos não diferem em relação ao escore das categorias $3(p=0,231)$ e $4(p=0,104)$. Comparando o escore total nos dois grupos de estudantes, verificamos que o grupo de 2007 apresenta valor de escore significantemente menor que o do grupo de $2008(p=0,013)$.

\section{DISCUSSÃo}

O sexo feminino, como era de se esperar, predominou nos dois anos analisados; a faixa etária prevalente corresponde à esperada para término do curso de graduação em enfermagem, mostrando que a maioria dos estudantes conclui o curso em quatro anos.

Analisando o Preparo do enfermeiro para supervisionar o estágio dos alunos, observamos, de modo geral, que os enfermeiros dispensaram atenção e ajudaram os estudantes a encontrarem oportunidades de aprendizagem, o que mostra que os enfermeiros se esforçaram para favorecer o aprendizado dos alunos, estimulando-os a aprenderem e encorajando-os a participarem da dinâmica de trabalho, consequentemente, contribuíram para otimização do tempo.

Embora os estudantes tenham considerado que os enfermeiros têm segurança para assumir a condução do ensino prático, não houve clareza quanto aos enfermeiros assumirem integralmente o acompanhamento do estágio. Essa divergência entre os estudantes pode ter sido entendida como a ausência total do docente junto ao aluno no período de estágio, o que não é o anseio da maioria dos graduandos.

Não se pôde concluir se os enfermeiros tinham receio de que os alunos cometessem falhas, o que deve ser mais investigado, pois a segurança do enfermeiro é percebida pelo estudante, e ambos devem estabelecer um vínculo de confiança, de modo que o enfermeiro minimize a possibilidade de erros sem cercear a iniciativa.

Isso implica pensar, não só na articulação teóricoprática, mas, também, nas relações compartilhadas de serviços de saúde e escola e na responsabilidade do educador, o que envolve ações políticas e pedagógicas $^{(10)}$.

A competência dos enfermeiros para orientação dos estudantes ficou evidenciada por terem domínio técnico de suas atividades, fornecerem orientações objetivas, consistentes e não apresentarem dificuldades para compartilhar seu conhecimento, nem tampouco, precisarem ensinar conteúdos para os quais não foram preparados.

Importante destacar, entretanto, que apesar da capacitação do enfermeiro demonstrada nesses atributos, não se pôde definir, claramente, se houve divergência nas orientações ministradas aos alunos, bem como entre a orientação do enfermeiro e as atividades executadas por técnicos e auxiliares de enfermagem. Apesar dessa incongruência, os enfermeiros estão preparados para acompanhar os graduandos que se sentem seguros com a supervisão do enfermeiro.

Para isso, é essencial que o enfermeiro atualize-se constantemente, de modo a influenciar positivamente seu grupo e criar um ambiente de crescimento individual e coletivo, incorporando novas tecnologias ${ }^{(11)}$, além do que, como coordenador da assistência deve atualizar-se continuamente e atuar dando exemplos, com coerência entre ação e discurso e com decisões baseadas em justiça, 
o que the confere credibilidade perante a equipe de enfermagem ${ }^{(12)}$.

O Relacionamento interpessoal do aluno com a equipe de enfermagem foi caracterizado pelo respeito e interação. Inquestionavelmente, as relações interpessoais influenciam o desempenho humano no ambiente de trabalho e, portanto, o alcance das metas da organização, tanto quanto influencia a integração e o desenvolvimento do estudante. O estágio é um campo fértil de interação e impõe ao aluno a experiência de desenvolver a competência de saber conviver. Quando não há entrosamento ou manifestam-se sentimentos de desconfiança e rejeição ocorre um afastamento entre as pessoas e consequente prejuízo ao aprendizado.

Por sua relevância, os processos relacionais merecem mais atenção nos currículos, pois eles expressam, implicitamente, a concepção de saúde e educação(13).

Quanto ao Aproveitamento do aluno no campo, o ensino prático, além de proporcionar a construção gradativa da identidade profissional, atendeu às expectativas dos estudantes e as atividades realizadas aos objetivos de cada disciplina; os estudantes conseguiram relacionar teoria e prática durante os estágios, o que é essencial, pois uma das grandes preocupações do ensino de enfermagem é a dicotomia teoria e prática.

Estudo realizado com egressos de um curso de aprimoramento em enfermagem mostrou que o estágio proporcionou a aplicação da teoria na prática e atendeu às suas expectativas $^{(14)}$.

A prática contribuiu para além do aprendizado técnico, o que se considera bastante positivo, uma vez que a formação do aluno não se restringe ao conhecimento técnico mais voltado ao modelo biomédico de atenção à saúde. No perfil profissiográfico dessa Escola espera-se a formação de um enfermeiro crítico e reflexivo, o que está ratificado na $\mathrm{DCN}^{(2)}$.

Neste sentido, na DCN e na prática docente, a valorização dos aspectos técnicos e científicos dos formandos não podem suplantar os aspectos sociovalorativos ${ }^{(3)}$.

Os ambientes que oferecem situações-problemas que desencadeiam as dúvidas e o pensamento são fundamentais para aprendizagem, bem como, centrar o ensino em tarefas autênticas, relevantes e úteis que forneçam níveis apropriados de complexidade ${ }^{(15)}$. Ademais, o enfoque problematizador na formação em saúde mobiliza, significativamente, os processos de aprendizagem, alavancando, entre outros, o interesse e a motivação do educando(16).

\section{Das Condições institucionais oferecidas ao aluno,} os recursos materiais disponíveis foram suficientes às demandas dos estudantes. Os manuais consultados foram úteis para o aprendizado. Mais do que a consulta aos manuais é necessário que haja uma leitura significativa, contextualizando e atribuindo significado à leitura ${ }^{(17)}$, desse modo, a articulação do enfermeiro é importante para auxiliar o aluno a compreender as informações constantes.

Embora não tenha havido clara posição quanto à disponibilidade de tempo dos enfermeiros para acompanhamento dos alunos, não se evidenciou que a dinâmica da unidade impedisse esse acompanhamento. Por outro lado, afirmaram não ter havido falta de recursos humanos que prejudicasse o desenvolvimento do estágio, sendo que a unidade proporcionou oportunidades para realização dos procedimentos previstos.

Importante, ainda, a integração docente-assistencial caracterizada pelo fato de enfermeiros e professores apresentarem boa comunicação e interação. Apesar disso, na opinião dos graduandos de 2007, os enfermeiros precisam conhecer mais os objetivos dos estágios. De qualquer modo, é importante aprofundar essa investigação já que é destinado aos enfermeiros o acompanhamento direto do aluno no campo de estágio do HUUSP, sendo que, em determinados estágios, ele fica sob supervisão direta do enfermeiro.

O desenvolvimento das competências deve ser oportunizado em situações que o graduando possa argumentar e expressar suas idéias, de forma que aprenda a analisar, refletir e se responsabilize por seu aprendizado contínuo. Nesse sentido, os achados remetem ao questionamento acerca dos motivos pelos quais uma significativa parcela de estudantes não conseguiu discutir com os enfermeiros situações presenciadas que desrespeitaram aspectos éticos, já que a maioria dos graduandos concordou que houve interação e entrosamento entre alunos e equipe de enfermagem. Talvez, o estudante tema se manifestar pela possibilidade de ser mal interpretado pelos enfermeiros, evitando, assim, algum confronto de ideias.

Esse resultado merece destaque, pois, embora, haja no atual currículo duas disciplinas de ética, não se pode atribuir a elas toda a responsabilidade de formação ética nos estudantes, uma vez que eles desenvolvem a competência ética na atuação prática e no exemplo dos profissionais, sendo o cotidiano o espaço mais fértil para reflexão e fortalecimento dos princípios que norteiam a conduta ética. A tomada de decisão ética é baseada em valores e princípios que justificam e explicam os motivos pelos quais 
um ato pode ser considerado adequado ou inadequado.

Conhecer a situação e reconhecer os valores e crenças envolvidos na situação e empregar instrumentos éticos e legais proporcionam tomadas de decisões respaldadas por preceitos éticos, fortalecendo o compromisso profissional ${ }^{(18)}$. Os profissionais da saúde, no entanto, podem não ter experiência para reconhecer um problema ético quando se deparam com ele. É importante, que o ensino da ética transcenda a questão pedagógica e seja explicitado a fim de que os profissionais desenvolvam a competência ético-política(19).

O Sistema de Assistência de Enfermagem (SAE) foi considerado um importante instrumento de aprendizagem para os estudantes, sendo que os enfermeiros, preparados para ensinar o Diagnóstico de Enfermagem, estimularam os alunos a desenvolverem o raciocínio clínico.

O HUUSP é uma das poucas entidades de saúde do país na qual o Diagnóstico de Enfermagem e o Sistema de Assistência de Enfermagem (SAE) estão implementados como parte real do Processo de Enfermagem. Por ser um hospital escola, esses fatores tornam-se valiosos facilitadores na aprendizagem do estudante. Além disso, vem aprimorando os enfermeiros nessa competência, o que pode explicar a maior favorabilidade com relação a esses atributos ter ocorrido em 2008.

De modo geral, em 2008, as posições favoráveis são mais bem definidas e mais favoráveis do que em 2007. A continuidade e regularidade dessa avaliação, bem como a verificação de existência de relação entre variáveis poderá trazer mais informações a serem analisadas no conjunto.

\section{CONSIDERAÇÕES FINAIS}

Essa discussão não pretendeu, num primeiro momento, esgotar o assunto, mas sim, abrir caminhos para investigações e análises pormenorizadas, com o objetivo de aprimorar o campo com vistas à sua adequação ao projeto político-pedagógico da EEUSP, na formação dos futuros enfermeiros.

De modo geral, o graduando teve uma visão positiva das condições institucionais do campo de estágio do HUUSP, sendo pontos facilitadores do ensino prático, os recursos materiais e humanos; a atuação do enfermeiro que estimulou e criou oportunidades aos estudantes, mostrando-se atencioso para com os mesmos e preparado para assumir o estágio.

Quanto aos pontos de vulnerabilidade, percebeu-se que os enfermeiros precisam conhecer melhor os objetivos do estágio, apesar destes objetivos terem sido alcançados.

Outra possibilidade de análise para maior clareza e aprimoramento do diagnóstico iniciado nesse estudo é proceder a uma avaliação ao final de cada disciplina, aumentando o poder de identificação de necessidades e potencialidades. A abordagem geral do campo de estágio, nas proposições do instrumento, pode ter interferido na significativa proporção de neutralidade em algumas respostas obtidas.

Destacando o expressivo envolvimento dos enfermeiros no processo educacional e a percepção que têm de seu processo de trabalho, estes profissionais devem participar da avaliação, fornecendo significativos subsídios para efetuar o diagnóstico situacional. Desta forma, o questionário será ampliado de modo que possam participar da avaliação, os enfermeiros do campo de estágio e os docentes da EE responsáveis pelas disciplinas.

enfermeiro. Rev. Eletr. Enf. [Internet]. 2010;12(3):562-6. Available from: http://www.fen.ufg.br/revista/v12/n3/v12n3a21.htm.

6. Chirelli MQ, Mishima SM. A formação do enfermeiro críticoreflexivo no curso de enfermagem da Faculdade de Medicina de Marília - FAMEMA. Rev Lat Am Enfermagem [Internet]. 2003 [cited 2011 set 30];11(5):574-84. Available from: http://www.scielo.br/pdf/rlae/v11n5/v11n5a03.pdf.

7. Rothbarth S, Gonçalves WLD, Peres AM. O desenvolvimento de competências gerenciais do enfermeiro na perspectiva de docentes de disciplinas de Administração aplicada à Enfermagem. Texto Contexto Enferm [Internet]. 2009 [cited 2011 set 30];18(2):321-9. Available from: http://www.scielo.br/pdf/tce/v18n2/16.pdf.

8. Pereira ALF. As tendências pedagógicas e a prática educativa nas ciências da saúde. Cad Saude Publica [Internet]. 2003 [cited 2011 set 30];19(5):1527-34. Available from: http://www.scielo.br/pdf/csp/v19n5/17825.pdf.

9. Polit DF, Beck CT. Fundamentos de pesquisa em enfermagem: avaliação das evidências para a prática de enfermagem. 7th ed. Porto Alegre: Artmed; 2011.

10. Casate JC, Corrêa AK. Vivências de alunos de enfermagem em estágio hospitalar: subsídios para refletir sobre a humanização em 
saúde. Rev Esc Enferm USP [Internet]. 2006 [cited 2011 set 30];40(3):321-28. Available from: http://www.scielo.br/pdf/reeusp/v40n3/v40n3a01.pdf.

11. Costa RA, Shimizu HE. Estudo das atividades desenvolvidas pelos enfermeiros em um hospital-escola. Rev Esc Enferm USP [Internet]. 2006 [cited 2011 set 30];40(3):418-26. Available from: http://www.scielo.br/pdf/reeusp/v40n3/v40n3a14.pdf.

12. Amestroy SC. Liderança como instrumento no processo de trabalho da enfermagem [dissertation]. Rio Grande: Programa de Pós-Graduação em Enfermagem/FURG; 2008.

13. Fagundes NC, Burnham TF. Discutindo a relação entre espaço e aprendizagem na formação de profissionais de saúde. Interface (Botucatu) [Internet]. 2004 [cited 2011 set 30];9(16):105-14. Available from: http://www.scielo.br/pdf/\%0D/icse/v9n16/v9n16a09.pdf.

14. Calicchio LCN, Kobayashi R, Ayoub AC, Leite MMJ. Aprimoramento profissional em enfermagem cardiovascular: avaliação na ótica dos egressos de 1981 a 2004. Rev. Eletr. Enf. [Internet]. 2008 [cited 2011 set 30];10(1):77-86. Available from: http://www.fen.ufg.br/revista/v10/n1/v10n1a07.htm.

15. Depresbiteris L. Avaliando competências na escola de alguns ou na escola de todos? [Internet]. Rio de Janeiro: SENAC; 2002 abr 10 [cited 2011 set 30]. Available from: http://www.senac.br/BTS/273/boltec273d.htm.

16. Batista N, Batista SH, Goldenberg P, Seiffert O, Sonzogno MC. O enfoque problematizador na formação de profissionais de saúde. Rev Saude Publica [Internet]. 2005 [cited 2011 set 30];39(2):231-7. Available from: http://www.scielo.br/pdf/rsp/v39n2/24047.pdf.

17. Oliveira $K L$, Santos AAA. Compreensão em leitura e avaliação da aprendizagem em universitários. Psicol. Refl. Crít. [Internet]. 2005 [cited 2011 set 30];18(1):118-24. Available from: http://www.scielo.br/pdf/prc/v18n1/24825.pdf.

18. Massarollo MCKB, Fernandes MFP. Ética e gerenciamento em enfermagem. In: Kurcgant $P$ (coordenadora). Gerenciamento em enfermagem. Guanabara Koogan; Rio de Janeiro; 2010. Cap. 2, p. 14-25.

19. Souza ML, Sartor VVB, Prado ML. Subsídios para uma ética da responsabilidade em Enfermagem. Texto Contexto Enferm [Internet]. 2005 [cited 2011 set 30];14(1):75-81. Available from: http://www.scielo.br/pdf/tce/v14n1/a10v14n1.pdf.

Artigo recebido em 31.08.2010.

Aprovado para publicação em 29.08.2011.

Artigo publicado em 30.09.2011. 